\title{
Machado de Assis e Portugal: representação e circulação oitocentistas
}

\author{
Machado de Assis and Portugal: representation and 19th century movement \\ Valdiney Valente Lobato de CASTRO* \\ Faculdade Estácio do Amapá
}

\begin{abstract}
RESUMO: A vasta produção machadiana que se estende por cerca de meio século em diferentes gêneros circulou muito além dos domínios da Cidade da Corte, atingindo tanto províncias brasileiras quanto outros países, graças à democratização da leitura a partir da proliferação dos periódicos. Se a presença de traços lusitanos aparece com raridade na prosa de ficção machadiana, em terras portuguesas a obra do eminente escritor deixa rastros em vários jornais do século XIX. A proposta deste trabalho é analisar esses dois suportes: a obra do autor brasileiro e os jornais portugueses, a fim de perceber nesses a presença de obras machadianas e naquela a imagem desenhada da terra lusitana. Essa análise não só possibilitará discutir o espaço de autores brasileiros em folhas portuguesas, como também ajudará a refletir sobre o trânsito de obras entre os dois países.
\end{abstract}

PALAVRAS-CHAVE: Conto. Machado de Assis. Jornal. Século XIX. Portugal.

\begin{abstract}
The vast Machadian production spanning half a century in different genres has circulated far beyond the domains of the Court City, reaching both Brazilian provinces and other countries, thanks to the democratization of reading from the proliferation of periodicals. If the presence of Lusitanian traits appears with rarity in Machado fiction prose, in Portuguese lands the work of the eminent writer leaves traces in several newspapers of century XIX. The purpose of this work is to analyze these two supports: the work of the Brazilian author and the Portuguese newspapers, in order to perceive in these the presence of Machado works and in that the drawn image of the Lusitanian land. This analysis will not only make it possible to discuss the space of Brazilian authors in Portuguese pages, but will also help to reflect on the transit of works between the two countries.
\end{abstract}

KEYWORDS: Tale. Machado de Assis. Newspaper. XIX century. Portugal.

\section{Machado e Portugal: fartos contatos e poucas publicações}

\footnotetext{
${ }^{*}$ Professor Doutor em Letras pela universidade Federal do Pará, Professor Titular da Faculdade Estácio do Amapá. E-mail: valdineyvalente@hotmail.com
} 
Relacionar Machado de Assis e Portugal é uma tarefa tão árdua quanto audaciosa, isso porque, além de o autor ter ambientado suas narrativas quase totalmente no Rio de Janeiro e seus arredores, também há poucos registros de estudos sobre Machado em terras portuguesas, o que, de fato, esmorece a investigação.

Quanto às narrativas, em análise aos quatro romances iniciais do autor, há total ausência de referência a Portugal. Apenas em Memórias Póstumas de Brás Cubas, já na época em que o Brasil estava a poucos anos do advento da República, há duas tímidas alusões a Lisboa: quando Vilaça lembra que ouviu Bocage declamar seus versos, em fins do século, no botequim do Nicola e no momento em que o personagem título vai para Coimbra bacharelar-se em Direito. Mas, mesmo nesse caso, o relato é furtivo, restringe-se apenas à passagem de Lisboa para Coimbra, os estudos, e depois o narrador esclarece que não vai se deter em episódios europeus, porque o romance trata-se de memórias e não de um diário de bordo.

Se Brás Cubas, mesmo tendo morado em Lisboa, não oferece um relato mais amplo, nos três romances posteriores a alusão a Portugal é ainda mais modesta: José Dias diz ter amigos em Lisboa (Dom Casmurro), Rubião lê o jornal Correspondência de Portugal, no Carceler (Quincas Borba), e Batista manuseia uma carta do Conde de Oeiras, escrita ao ministro de Portugal, na Holanda (Esaú e Jacó).

A relevância mais significativa acontece no último romance, Memorial de Aires: Tristão, afilhado do casal Aguiar, mora em Lisboa, onde se forma em medicina. Ao voltar para o Brasil, mantém vínculo com alguns jornais portugueses em que colaborava e também com alguns chefes da cidade que pretendem elegê-lo deputado; daí recebe regularmente cartas da capital portuguesa, instando pela sua volta. E isto é tudo. Não se esmiúçam os assuntos das muitas cartas que são recebidas pelo jovem médico; apenas no final do romance, quando ele retorna à cidade lusa, já desce do paquete deputado. Dessa forma, Lisboa é apenas um ponto de referência apresentado na obra sem quaisquer especificidades.

Nos contos, Portugal aparece apenas em "Rui de Leão" (saído no Jornal das Famílias nos meses de janeiro a março de 1872), depois reescrito e renomeado como "O imortal" (publicado de julho a setembro de 1882 n’A Estação): finalmente, o personagem homônimo, entre as várias viagens, vai a Lisboa no ano de 1730 para ser apresentado ao rei D. João V, o que não ocorre. Há algumas peripécias entre países, a 
passagem por Portugal é rápida, mas, quando comparada com as outras obras, é o que há de mais relevante, pois há uma descrição de um personagem que anda pelas ruas da capital portuguesa e cita um marco do país, nem que seja apenas o Tejo.

Se, na prosa de ficção, Machado foi econômico ao tratar de Portugal, o mesmo não ocorre em suas correspondências; há cartas trocadas com Francisco Gomes de Amorim, Manuel de Araújo, José Feliciano de Castilho, António Feliciano de Castilho, José Cardoso Vieira de Castro, Francisco Ramos Paz, Luís Cândido Cordeiro Pinheiro Furtado Coelho, Eduardo de Lemos, Julio César Machado, Joaquim de Melo, Artur Napoleão dos Santos, Eça de Queiroz, Francisco Filinto de Almeida, Henrique Samuel de Nogueira Rodrigues Chaves, Ernesto Pego de Kruger Cibrão, Carlos Malheiro Dias, Fernando António Pinto de Miranda e António Moutinho de Sousa, além da família Xavier de Novais, principalmente Miguel de Novais, com quem manteve rotineira correspondência.

A maioria desses portugueses travou relações com Machado em visita ao Brasil, outros como Eça apenas se comunicaram por cartas. Apesar de a relação com o grande escritor português nunca ter desfeito a nesga de animosidade entre os dois e de até mesmo os jornais brasileiros terem visto excessiva severidade na crítica de Machado ${ }^{1}$, a relação deste com os demais escritores portugueses com quem se correspondeu sempre foi de extrema cortesia. Gomes de Amorim, por exemplo, em carta de 28 de junho de 1866, afirma que o nome do autor atravessou os mares e é conhecido como uma das glórias brasileiras.

Essa declaração elogiosa é motivada pelo agradecimento do missivista por Machado ter publicado um artigo comentando seus versos e, durante anos, o português trocou cartas com o autor brasileiro, tendo interesse tanto em publicação quanto nas críticas do autor. Também os irmãos Castilho mantiveram relações amáveis com Machado; Antonio Feliciano, na "advertência" da tradução de Fausto (1872), alude ao autor como o maior adorno das letras brasileiras, consagração já feita pelos irmãos na dedicatória da tradução da Ars Amatoria, de Ovídio, isso ainda em 1867 (SARAIVA, 2009).

\footnotetext{
${ }^{1}$ Eça de Queiroz, após a crítica, elegantemente escreve ao autor elogiando o brilhante texto, o que assevera o valor de seu romance, e pede, em seu nome, para Machado agradecer a excelente recepção que sua obra alcançou no Brasil. Não comenta sobre a acusação de plágio feita por Machado. Anos mais tarde, quando Eça faleceu, o autor de Dom Casmurro escreveu a Henrique Chaves que o português era "o melhor da família, o mais esbelto, o mais válido".
} 
Essa consideração foi construída também devido aos livros do autor circularem em terras portuguesas: Miguel de Novais, por exemplo, em carta a Machado, diz que ainda não leu detalhadamente o livro que lhe foi enviado, Papéis Avulsos, porque ele está sendo lido por Ramalho Ortigão.

Obviamente que essas relações legaram ao autor um reconhecimento em terras lusitanas. Prova disso é a nomeação de Machado como membro da Academia de Ciências de Lisboa, noticiada em 25 de julho de 1904, n'O Pharo (1904, p. 4)l: "Sabese por notícia chegada de Portugal, que o ilustre homem de letras sr. Machado de Assis foi nomeado membro da Academia Real das Sciencias de Lisboa" . Também o jornal Comércio do Amazonas, em 14 de agosto de 1900, já divulgava a notícia para o norte do país:

\footnotetext{
Vai ser proposto para sócio da Academia Real das Sciencias de Lisboa o eminente escritor brasileiro Machado de Assis. Póde desde já asseverar-se que tal proposta será aprovada unanimemente.

O illustre autor das Memórias Póstumas de Braz Cubas não é candidado: sim, a sua nomeação terá o valor especial de uma verdadeira demonstração de apreço. (COMERCIO DO AMAZONAS, 1900, p. 03)
}

A proposição do autor para a Academia Portuguesa foi feita desde 13 de dezembro de 1900, quando foi anunciada a proposta de candidatura ao lado de José Veríssimo e Sílvio Romero, justamente os dois principais nomes do início da crítica machadiana. O presidente da academia justifica o nome dos três brasileiros por trabalhos desenvolvidos nos campos jornalísticos, críticos e/ou apenas literários.

$\mathrm{Na}$ ata de sessão de 23 de junho de 1904, o presidente anuncia que há um parecer com o nome de Machado para ser votado, mas, como não havia o número de sócios suficientes, a votação foi adiada para a próxima reunião. E, na sessão de 25 de julho de 1904, o nome do autor foi aprovado por unanimidade. Na ata, consta o parecer lavrado pelo sócio efetivo José de Sousa Monteiro. Ao longo texto, três aspectos de Machado são destacados: a fecundidade de sua pena, com tanta produção em gêneros variados, a faculdade do trabalho e o humor.

Ao citar as obras, lista os cinco primeiros volumes de contos e, mais adiante, ao caracterizar o humor, assim expressa:

É isso com certeza que desperta em nós a leitura das páginas tão finamente pensadas quanta vez e tão finamente escriptas de suas novellas de maior alcance, de seus contos de mais breve tomo, que prefiro e muito áquellas, das graciosas e delicadamente irônicas páginas de Um Alienista ou de O Segredo 
do Bonzo, por exemplo. Ironia sem crueza, sorriso que se abre de longe em longe em riso franco, mas que nunca se escancara em gargalhada ruidosa e brutal. (ACADEMIA REAL DAS CIÊNCIAS, 1910, p. 145).

E, mais adiante, afirma que "os maiores escriptores do Brasil são os que menos se apartam pela língua" (ACADEMIA REAL DAS CIÊNCIAS, 1910, p. 146); daí, para o crítico, Machado é um destaque pelo uso do português, apesar de haver em seus textos "brasileirismos". E exemplifica:

\begin{abstract}
"Segredo do Bonzo", por exemplo, onde sua existência fora incompatível com o propósito engenhoso do escriptor, afiança que só os commeteria, quando não é por inevitável lapso de sua penna experiente e certa, por indeclinável necessidade. No encantador capítulo a que alludo e que attribue a Fernão Mendes Pinto há um: pomada e pomadista. Mas o escriptor explica a brazielira e ingrata neologia n'uma nota. Era necessária. (ACADEMIA REAL DAS CIÊNCIAS, 1910, p. 146)
\end{abstract}

O parecer foi lavrado em 7 de junho de 1901 e a secção de literatura o aprovou em 3 de junho de 1904 pelas mãos de Silveira da Motta e Henrique Lopes de Mendonça, que só depois o submeteram à votação da academia. Nos argumentos do parecerista, nenhum romance é comentado nem mesmo como exemplo, talvez porque, como se lê na citação, José de Sousa Monteiro afirme preferir os contos e demonstra a leitura desses textos. Vale acrescentar que, em outro momento do parecer, ele ainda diz que não conhece Machado de Assis e lamenta por isso. Quanto ao "ingrato" brasileirismo de Machado, apesar de haver um elogio à "pena experiente" do autor, não se pode deixar de notar a rusga com a língua, tanto na afirmação sobre a necessidade de não se apartar da língua de Portugal, quanto na frase final da última citação.

Além da consagrada instituição, o nome de Machado penetrou em alguns jornais e revistas portuguesas. Em 1865, a Revista Contemporânea de Portugal e Brasil publicou parte do poema "Versos a Corina", saído no ano anterior em Crisálidas. Há muito desalinho quanto a essa informação: Ivan Teixeira (1987) diz que foi em uma cidade do Porto, sem afirmar de qual se trata, e Raymond Sayers afirma que Ramalho Ortigão coletou a poesia para publicar em um artigo intitulado "Versos de Machado de Assis", no Jornal do Porto, em 1884.

Desse mesmo livro, Antero de Quental retira a poesia "Fé" (p. 201-202) para integrar sua coletânea Tesouro Poética da Infância, saída em 1883. E, em carta de fins de 1880, escreve: "Do Machado de Assis só pude alcançar as Crisálidas, de que gostei 
muito, mas nada colhi que me servisse" (SAYERS, 1972, p.12), provavelmente porque o autor português buscava poesias que ele pudesse enquadrar dentro do universo infantil.

Em 1877, o Parnaso Português Moderno², de Teófilo Braga, publicou duas poesias do autor: "O leque” (p. 203) e "Quando ella falla" (p. 202), ambas extraídas de Falenas (1870).

Outras poesias do autor aparecem no Novo Almanach de Lembranças LusoBrazileiro, editado por Lallemnat Frères, em Lisboa ${ }^{3}$. Em 1872, sai "O Verme" e "Coração triste fallando ao sol", oitavo poema de "Lira Chinesa", aparece na edição de 1877. O soneto “A amante de Camões", que pertence à poesia "Camões" é publicado em 1881 e "Quando ella falla" em 1900. Todos esses poemas foram publicados em Falenas, à exceção de "Camões”, lançado em Ocidentais.

No número 77 de 19 de setembro de 1897, no semanário ilustrado Branco e $\mathrm{Negro}^{4}$, é publicada a poesia "Mosca Azul" (de Ocidentais), juntamente com uma imagem do autor (Branco e Negro, 19 set. 1897, p. 397), retiradas do livro de Valentim Magalhães, A Literatura Brazileira (1896), provavelmente porque nessa edição havia um estudo sobre os autores do realismo e Machado é classificado na categoria "Os desorientados", justamente por não se enquadrar nos moldes dessa literatura.

Certamente, a poesia machadiana atingiu outros suportes dos quais não restaram evidências. Os jornais brasileiros oferecem dois rastros: em 9 de setembro de 1874, saiu uma nota no jornal carioca $O$ Globo, convidando o autor para integrar o time de colaboradores da Revista Occidental, de Lisboa. No entanto, nos dois volumes que reúnem as edições de 1875, não há qualquer publicação do autor. Também no Jornal do Commercio, de 19 de outubro de 1880, foi lançada uma nota sobre o livro Marquês de Pombal, de José Maria Latino Coelho, que sairia brevemente, onde se lê que Machado de Assis seria colaborador.

\footnotetext{
${ }^{2}$ Essa publicação é uma volumosa antologia reunindo poetas líricos portugueses e brasileiros e, devido à quantidade de escritores, apresenta poucos textos de cada um deles. Com cerca de 400 páginas e editada por Francisco Arthur da Silva, começa com um longo ensaio sobre a poesia moderna portuguesa. ${ }^{3}$ O Novo Almanach Luso Brazileiro era editado anualmente e direcionado para o ano seguinte. A edição anual começava com um relato biográfico e uma foto de um autor e muitos brasileiros estiveram nessa seção, como Gonçalves Dias, Álvares de Azevedo e Castro Alves. A obra, devido à periodicidade, era volumosa contendo até 300 páginas.

${ }^{4}$ Esse suporte existiu por três anos, de 1896 a 1898 com periodicidade regular. Os volumes iniciavam com a apresentação da história de um local português, seguido de algumas poesias de portugueses e brasileiros, várias ilustrações (fotografias e pinturas) e raros anúncios.
} 
Se a poesia conseguiu atingir vários suportes, com ou sem a autorização do autor, a prosa pouco se revelou. Apenas em A Folha Nova, do Porto, no período de 12 de outubro a 22 de novembro de 1883, foram publicados os capítulos de Memórias Póstumas de Brás Cubas, mas apenas até o XXVIII, intitulado "Contanto que...". No primeiro número, o editor assim anunciou a publicação do folhetim:

\begin{abstract}
O notável romancista e poeta brasileiro Sr. Machado de Assis, ofereceu ao nosso amigo Moutinho de Sousa, durante a última e rápida estada deste $\mathrm{Sr}$. no Rio de Janeiro o seu romance, Memórias Póstumas de Brás Cubas, com a permissão de ele o publicar num periódico de Portugal, a seu gosto. O nosso amigo escolheu a Folha Nova, honra que muito nos penhora e que principiamos a merecer inserindo o primeiro folhetim do notável romance. (A FOLHA NOVA, 1883, p. 1)
\end{abstract}

Não há registros de contos ou de crônicas do autor, só raros comentários elogiosos de alguns portugueses se referindo a textos machadianos. Os livros de Machado foram postos à venda por Ernesto Chardron em 1879, 1880 e 1881, conforme consta na Bibliografia Portuguesa e Estrangeira, mas provavelmente não provocaram alarde. Há várias suposições para o fato de a literatura brasileira chegar tão modestamente em terras portuguesas. Pedro Calheiros, da Universidade de Aveiros, publicou na revista Travessia em 1993 um estudo para mostrar o quanto a obra machadiana era desconhecida em Portugal. Apesar de não discorrer sobre as publicações do autor em periódicos, exatamente por acreditar que o resultado não valeria o esforço, o professor assegura que os portugueses não tiveram conhecimento da obra machadiana.

Raymond Sayers (1972) apresenta várias razões para esse desconhecimento: o primeiro motivo é a concorrência com os livros franceses, que dominavam o cenário de leitura, não só na França como em todos os outros países. A quantidade de publicações e o assunto das narrativas dominavam os leitores que preferiam as edições francesas saídas em terras lusitanas, o que pode explicar o porquê da interrupção de Memórias Póstumas de Brás Cubas: a excepcionalidade da narrativa pode não ter agradado aos leitores.

Outro dilema era a dificuldade de acesso a livros brasileiros, até mesmo nos anúncios que transbordam em vários periódicos do século XIX; a existência de uma obra do Brasil é raríssima e, quando assim acontece, a preferência é pelas poesias. 
Segundo Sayers, só com os esforços de Ernesto Chardron, livreiro estabelecido no Porto, é que se começa a vender livros brasileiros, mas ainda são poucos os títulos.

Vários críticos que tentaram publicar sobre as obras brasileiras encontraram dificuldade. Na seção "Bibliografia Brasileira", da revista O Brasil, Pinheiro Chagas lamenta que é mais fácil estudar um livro chinês traduzido para o francês do que um brasileiro, porque as únicas novidades que vêm do Brasil são "café, açúcar e bananas" (O Brasil, 1873, p. 2). Também Antero de Quental, na organização da coletânea já mencionada, queixa-se da dificuldade de acesso às obras brasileiras em carta a Joaquim de Araújo, provavelmente por isso no final da década de 1880, enquanto no Brasil a prosa machadiana estava em evidência, em Portugal ainda se tratava das poesias.

É mesmo Antero que comenta outra razão para o impasse. Sayers (1972) destaca uma carta do poeta português em que este aponta o motivo linguístico: como a língua brasileira ia se diferenciando da portuguesa, ela parecia incorreta ao ouvido português. No entanto, isso ainda não justifica a ausência dos textos machadianos, pois os críticos portugueses sempre elogiaram seu texto.

Na edição de 4 de agosto de 1895, o jornal A Madrugada, em continuidade ao artigo "Literatura Brasileira", assinado pela direção, apresenta o motivo mais plausível:

No Brasil lê-se quase tudo que aparece de antigo e moderno nas vitrines das livrarias lisboetas, o que infelizmente não se dá em Portugal relativamente aquele país. E porque? A quem cabe a culpa? Aos editores e aos próprios autores brasileiros. Raramente se encontram nas livrarias portuguesas obras impressas no Brasil, e se algum mais ousado se atreve a mandá-las vir, tem, de antemão calculado o prejuízo de que há de ter, porque os preços das mesmas variam extraordinariamente, sendo publicadas lá e exportadas para aqui. Um volume de trezentas páginas (brochura) custa no Brasil, de quatro a seis mil réis fracos atualmente, e aqui, para encontrar venda ou saída, é preciso que o preço não exceda de cinco a seis tostões fortes. É forçoso pois que haja muita abnegação e sacrifício para que o gosto pela leitura de obras brasileiras deixe de ser uma ficção e se torne realidade. (A MADRUGADA, 1895, p.1)

Com periodicidade mensal, essa revista publicada em Lisboa era dirigida por Oscar Leal, circulava em Portugal, no Brasil e nas ilhas portuguesas, e tinha como detalhamento: "Revista Noticiosa, Crítica, Literária, Biográfica e Bibliográfica”. Com apenas 4 páginas, as edições eram totalmente voltadas para a literatura: iniciavam com 
uma matéria da própria direção, traziam uma boa quantidade de versos, notícias de publicação e biografia de alguns autores tanto portugueses quanto brasileiros.

O preço das edições brasileiras era caro, sem condições de concorrer com as francesas, que circulavam largamente em Portugal; daí entende-se porque Machado enviava seus livros aos amigos que residiam em Lisboa e também o seu desconhecimento pela grande maioria dos escritores e críticos.

No entanto, a despeito desse dilema, mesmo sem lançar contos em Portugal, alguns escritos publicados por portugueses, enquanto o autor era vivo, abordam levemente seus contos. Em 1860, Innocencio Francisco da Silva publica o Diccionario Bibliographico Portuguez com nota biobibliográfica sobre o autor e a lista de jornais onde Machado colaborava. Em 1884, essa edição foi revista e a lista das obras até então publicadas passou a incluir as três primeiras coletâneas, informadas por Joaquim da Silva Mello Guimarães, provavelmente correspondente do dicionarista.

Ao comentar sobre Os Deuses de Casaca, em um artigo datado de março de 1866, no Annuario do Archivo Pittoresco, Pinheiro Chagas, apesar de não tratar precisamente dos contos, assim apresenta Machado, antes de tratar da peça:

É uma individualidade sympathica! A juventude a transbordar dos versos em torrentes de apaixonado lyrismo, da crítica em fervente e ingenuo enthusiasmo! Elegancia despretenciosa no dizer! Sorriso fino, veia humorística, viveza de estilo, originalidade no pensamento! [...] é um dos mais distinctos, se não o mais distincto dos folhetinistas do império (ANNUARIO, 1866, p. 213)

Essa crítica foi transcrita no mês seguinte, precisamente em 15 de abril de 1866, no jornal brasileiro Semana Ilustrada, número 279, p.1229-1230. Todas essas exclamações foram feitas muito antes de serem publicados os livros com as prosas de ficção do autor, quando ainda colabora no Jornal das Famílias, com 27 anos.

Se as narrativas machadianas pouco abordaram as terras lusas, Machado estabeleceu frutíferos contatos com os portugueses, o que lhe rendeu a circulação de algumas obras suas em terras d'além mar, seja por meio de algumas poesias saídas nos jornais ou pelo envio dos exemplares aos seus amigos mais próximos. De todo modo, as relações conquistadas com o meio literário lusitano e essas esparsas publicações lhe possibilitaram ser nomeado como membro da Academia Real de Ciências de Lisboa, o que garante sua celebração em Portugal, o que não comum no século XIX. Além disso, 
tanto as relações entre os escritores quanto as publicações saídas nos periódicos portugueses ajudam a compreender o quanto a distância espacial entre os dois países era pequena ao se considerar as circulações de obras publicadas nas folhas avulsas e a entronização de Machado, bem como de outros escritores, em terras lusas.

\section{REFERÊNCIAS}

ACADEMIA REAL DAS CIÊNCIAS DE LISBOA. Boletim de Segunda Classe, v. 2), Lisboa, 1910.

A FOLHA NOVA, Rio de Janeiro, 1882, p.1

ALMANAQUE DE LEMBRANÇAS LUSO-BRASILEIRO, Lisboa.

A MADRUGADA, Lisboa, p.1, 4 ago 1895.

ANNUÁRIO do Archivo Pitoresco. Lisboa: Editora, 1966

ASSIS, Machado de. Memórias Póstumas de Brás Cubas. Disponível em:

http://www.dominiopublico.gov.br/download/texto/bn000167.pdf. Acesso em: 16 abr. 2017.

Quincas Borba. Disponível em:

http://www.dominiopublico.gov.br/download/texto/bn000106.pdf. Acesso em: 16 abr. 2017.

Dom Casmurro. Disponível em:

http://www.dominiopublico.gov.br/download/texto/bn000069.pdf. Acesso em: 16 abril 2017.

Esaú e Jacó. Disponível em:

http://www.dominiopublico.gov.br/download/texto/bn000030.pdf. Acesso em: 16 abril 2017.

Memorial de Aires. Disponível em:

http://www.dominiopublico.gov.br/download/texto/bn000025.pdf. Acesso em: 16 abril 2017.

Correspondência de Machado de Assis: Tomo I - 1860-1869. Org. Sergio Paulo

Rouanet, Irene Moutinho e Sílvia Eleutério. Rio de Janeiro: ABL, 2008.

Correspondência de Machado de Assis. Tomo II - 1870-1889. Org. Sergio Paulo

Rouanet, Irene Moutinho e Sílvia Eleutério. Rio de Janeiro: ABL, 2009. 
Correspondência de Machado de Assis: Tomo III - 1890-1900. Org. Sergio Paulo Rouanet, Irene Moutinho e Sílvia Eleutério. Rio de Janeiro: ABL, 2011.

Correspondência de Machado de Assis Tomo IV - 1901-1904. Org. Sergio Paulo

Rouanet, Irene Moutinho e Sílvia Eleutério. Rio de Janeiro: ABL, 2012.

Correspondência de Machado de Assis. Tomo V - 1905-1908. Org. Sergio Paulo

Rouanet, Irene Moutinho e Sílvia Eleutério. Rio de Janeiro: ABL, 2015.

AZEVEDO, Fabiano Cataldo de. Contributo para traçar o perfil do público leitor do

Real Gabinete Português de Leitura: 1837-1847. Ci. Inf., Brasília, v. 37, n. 2, p. 20-31, maio/ago. 2008. Disponível em: http://www.scielo.br/pdf/ci/v37n2/a02v37n2.pdf.

Acesso em: 16 abr. 2017.

AZEVEDO, Raul de. Confabulações: páginas de outrora e de hoje. Lisboa: Livrarias

Aillaud e Bertrand, 1919.

BRANCO E NEGRO, Lisboa.

BRANCO, Camilo Castelo. Dicionário Universal de Educação e Ensino. Porto:

Chardron, 1873.

CALHEIROS, Pedro. A Recepção de Machado de Assis em Portugal. Travessia, n 27

Litera(cul)tura.

COELHO, Jacinto do Prado. Dicionário de Literatura. Porto: Figueirinhas 1978.

CHAGAS, Pinheiro. Dicionário Popular. Lisboa Imprensa Nacional, 1876-1885.

Os deuses de casaca. Annuario do archivo pitoresco, p. 213, mar. 1866.

JORNAL do comercio, Rio de Janeiro, [ano?]

NOVO almanach de lembranças luso-brasileiro, Lisboa, v., n. dia mês ano..

O BRASIL, Lisboa, v. xx, n. dia mês ano

O GLOBO, Rio de Janeiro, v., n. dia mês ano.

O PHAROL, Rio de Janeiro, v. n., dia mês ano

PARNASO português moderno Lisboa, v., n.. dia mês ano.

REVISTA contemporânea de Portugal e Brasil, Lisboa, n., v. dia mês ano

REVISTA Ocidental, Rio de Janeiro, v. n. dia mês ano.

SARAIVA, Arnaldo. Machado de Assis em Portugal. In: CHAVES, Vania Pinheiro;

MOREIRA, Laura; CARDOSO, Solange Aparecida (Org.). Lembrar Machado de Assis: 1908-2008. Lisboa: LEPUL; 2009. 
SAYERS, Raymond. A Literatura Brasileira no Portugal Oitocentista: os críticos, os jornais, as revistas. Lisboa: Garcia de Orta, Revista da Junta de Investigações do Ultramar1972.

SILVA, Inocencio Francisco da. Dicionário Bibliográfico Português. Lisboa: Imprensa Nacional, 1860. 